\title{
Interacción de mercados laborales municipales en el estado de Tabasco: una aproximación a través del uso de modelos gravitatorios*
}

\section{Eduardo Juárez ${ }^{* *}$}

El conocimiento de las interacciones intraestatales, de tipo económico o demográfico, es relevante para la formulación de políticas estatales. La interacción de los mercados laborales municipales sólo puede ser captada a través de instrumentos que incorporen tanto sus potencialidades como las limitaciones surgidas de la ubicación territorial.

Este trabajo se basa en la hipótesis de que, si bien la ampliación de los mercados laborales se encuentra comandada por el incremento de la demanda de mano de obra, en contraparte, el incremento de la oferta de mano de obra en corto plazo, depende de su movilidad al despiazarse de otras localidades. En ese sentido, las alternativas de ampliación de mercados laborales, a nivel estatal, se distribuyen jerárquicamente y de forma descendente en función del volumen de la Población Económicamente Activa (PEA) de cada localidad, de la participación relativa de los desocupados dentro de ésta y de la distancia entre localidades. Bajo el razonamiento de que el crecimiento demográfico "sigue" al desarrollo económico, las posibilidades de ampliación de mercados laborales alternativos a aquellos de las principales localidades representan, adicionalmente, posibilidades de concentración de actividades económicas en lugares alternativos a las principales localidades del Estado.

Las localidades consideradas son las diecisiete cabeceras municipales del estado de Tabasco. Para modelar la interacción de los mercados laborales locales se utilizan modelos gravitatorios. Los puntos de producción de viajes son las cinco principales cabeceras municipales y los puntos de atracción son las restantes cabeceras municipales. ${ }^{1}$ Se utilizan informaciones a nivel local del XI Censo General de Población y Vivienda, 1990 (INEGI, 1991).

Los principales resultados indican que:

a) las interacciones más relevantes entre mercados laborales se localizan en la zona central del estado, donde Cunduacán y el eje TacotalpaTeapa juegan un importante papel como alternativas de ampliación de mercados laborales; trabajo.

* Agradezco los comentarios de Gustavo Garza a una versión previa de este

** Profesor-investigador del Centro de Estudios Demográficos y de Desarrollo Urbano de El Colegio de México.

${ }^{1}$ Las principales cabeceras municipales son: Cárdenas, Comalcalco, Macuspana, Tenosique y Villahermosa - capital estatal. Las cabeceras municipales restantes son: Balancán, Frontera, Cunduacán, Emiliano Zapata, Huimanguillo, lalapa, Jalpa de Méndez, lonuta, Nacajuca, Paraíso, Tacotalpa y Teapa. 
b) existe otro ámbito de interacción de mercados laborales en la zona sur, donde Emiliano Zapata juega un papel relevante dentro de ésta y como articulador con la zona central, y

c) la zona costera no representa una alternativa de empleo, desde el punto de vista de los principales municipios del estado.

\section{Introducción}

En la formulación de políticas al nivel estatal, el empleo tiene un papel privilegiado. Su relevancia, relacionada con aspectos de bienestar, se refuerza por el doble carácter como variable en estudio: el empleo representa, al mismo tiempo, al nivel de actividad económica y a la población.

Las relaciones económicas entre localidades pueden ser entendidas tomando en consideración solamente aspectos funcionales. Sin embargo, la interacción económica sólo puede entenderse incorporando al análisis las restricciones que impone la localización territorial de las actividades. Esta consideración es especialmente importante en el caso del empleo, donde la interacción de mercados laborales implica la movilidad de la mano de obra.

La incorporación de la variable territorial a los análisis de tipo funcional ha generado un área de conocimiento y desarrollo modelístico conocido como de metodologías multirregionales. En el campo demográfico se han desarrollado, por ejemplo, las metodologías multirregionales para proyecciones de población; en el económico, la metodología para el análisis de relaciones interindustriales multirregionales. En todo caso, para el estudio de la interacción entre puntos discretos en el territorio, se incorpora algún tipo de factor de "roce" o "fricción" dado por la distancia. Los modelos gravitatorios siguen el mismo razonamiento: entre dos localizaciones dadas, existen factores favorables para su interacción, y la distancia imprime un efecto de "repulsión". Estos elementos definen la magnitud de las interacciones y de los flujos posibles entre localizaciones alternativas.

Este trabajo, a través del uso de modelos gravitatorios, modela las interacciones entre los mercados laborales locales de las cabeceras municipales del estado de Tabasco, según informaciones de 1990. La hipótesis que guía el trabajo, es que las alternativas de ampliación de mercados laborales, desde la óptica de la oferta, a nivel estatal, se distribuye jerárquicamente, de forma descendente, en función del volumen de la Población Económicamente Activa (PEA), de la participación relativa de los desocupados de cada localidad y de la distancia que guardan las principales cabeceras 
municipales con las restantes. Así, las posibilidades de captación de desempleo, originado en las principales cabeceras municipales, se localizarían en aquellas de menor jerarquía, con menor porcentaje de PEA desocupada y más próximas. En términos operacionales, la anterior hipótesis implica considerar que la interacción entre mercados laborales depende del volumen de la PEA, del nivel de la desocupación en cada localidad y de la distancia entre localidades. El propósito es conocer, dentro del estado, cuáles podrían ser los posibles destinos de personas desocupadas de las principales localidades del estado, que posibiliten la ampliación de mercados laborales alternativos.

Se pretende mostrar que el uso de este tipo de modelaje permite generar elementos de juicio para indicar cuáles podrían ser las localizaciones más adecuadas de inversión productiva, esto es, generación de demanda de mano de obra, a partir de conocer las interacciones existentes entre mercados laborales en términos de la oferta.

Modelaje de las interacciones entre mercados laborales locales

El modelaje de las interacciones entre mercados laborales locales se realiza en tres etapas. La primera consiste en el ajuste de un modelo gravitatorio restringido en los orígenes, considerando la interacción dada por el total de la PEA de las localidades de origen y de destino donde la atractividad de cada punto de destino depende inversamente del nivel de desocupación. El ajuste del modelo permite contar con los parámetros del modelo para cubrir la siguiente etapa. La segunda, consiste en utilizar los parámetros resultantes del ajuste para realizar la predicción de la distribución del número de viajes que recibiría cada punto de destino, en función de los niveles de desempleo en cada una de las localidades productoras de viajes. La tercera etapa consiste en la aplicación predictiva de un modelo gravitatorio restringido tanto en los orígenes como en los destinos, para definir la magnitud específica de los flujos entre cada punto de origen hacia cada punto de destino.

A continuación se exponen las características generales de los tipos de modelos gravitatorios utilizados en este trabajo.

\section{Modelo gravitatorio con restricción en los orígenes}

Este tipo de modelo gravitatorio debe satisfacer la condición de que el total de viajes que se reciben en los puntos de atracción $\mathbf{j}$, sea igual al total de viajes que se generan en los puntos de produc- 
ción i, cuya magnitud es conocida. La expresión algebraica de esta restricción es: ${ }^{2}$

$$
\sum_{i=1}^{n} T i j=O i
$$

donde $j=1,2, \ldots, \mathrm{m}$ representa los puntos de atracción, Tij los viajes de los puntos de producción i que se reciben en j y Oi el total de viajes producidos desde i. La forma algebraica del modelo gravitatorio con restricción en los orígenes, expresa que el total de viajes que recibe un punto de atracción $j$ y los viajes procedentes del punto de origen i se relacionan de la siguiente manera:

$$
D j=K O i \frac{A j f(\mathrm{dij} j}{\sum_{i=1}^{n} A j f(\mathrm{dij})}
$$

donde $D j$ son los viajes recibidos en $j, K$ es una constante de proporcionalidad entre el total de viajes recibidos en todos los puntos de atracción de viajes y el total de viajes generados en todos los puntos de producción, Oi representa al total de viajes producidos en el punto de origen i, $A j$ representa a los factores positivos que afectan al flujo hacia $j$, llamado de factor de atractividad, y f(dijj representa a los factores negativos que afectan al flujo, bajo la forma de una función de distancia. En relación con la forma más general de los modelos gravitatorios, referida a la formulación newtoniana de la ley de gravedad, Oi y $D j$ representarían a las "masas" en interacción.

La constante $K$ se utiliza bajo la consideración de que, bajo la modalidad predictiva del modelo, serían desconocidos los viajes que específicamente estarían llegando al punto de atracción $j$. Así, se supone que existe una proporcionalidad entre los viajes que llegan a los destinos j y aquellos generados en los puntos i. La forma algebraica de esta formulación es:

$$
K=\sum_{j=1}^{n} D j / \sum_{i=1}^{n} O i
$$

El cociente que involucra a los factores de atractividad multi-

\footnotetext{
2 Identificamos los puntos de producción como aquellos de origen de los viajes y los de atracción como aquellos de destino de los viajes. Los origen es se refieren a los viajes generados en los puntos de producción y los destinos a los viajes recibidos en los puntos de atracción.
} 
pilcados por la función de distancia, en la fórmula (2), puede tener una interpretación probabilística. Indica cual es la probabilidad, en el modelo, de que los viajes generados en i se dirijan al destino j. Así, interpretando la fórmula (2), los viajes que recibe el punto de atracción $j$, procedentes del punto de producción de viajes, $i$, será el total de viajes producido en $\mathrm{i}, \mathrm{Oi}$, ponderado tanto por la probabilidad de viajes de $\mathrm{i}$ a $\mathrm{j}$ como por $K$, proporción del total de destinos en relación con el total de orígenes.

La función de distancia, $f$ (dij), implica siempre una relación inversa que expresa la "repulsión" entre los puntos considerados. Las dos formas que generalmente se utilizan para esta función son la exponencial negativa y la de potencias inversa. La primera se expresa como:

$$
f(\text { dij })=e^{- \text {udij }}
$$

la segunda, como:

$$
f(\mathrm{dij})=\frac{1}{d_{i j}^{a}}
$$

donde $a$ representa el parámetro de ajuste y dij la distancia entre i y j. La elección de un tipo de función de distancia depende de la magnitud que se quiera atribuir a la función de distancia como factor de "fricción" entre las localidades.

El ajuste de modelos requiere de alguna estimación de su bondad. En este trabajo, en que ajustamos un modelo a datos conocidos, utilizamos como medida de la bondad del ajuste el error promedio cuadrado $(E P C)$. Esta medida expresa el promedio de la suma de las diferencias cuadradas existentes entre los valores observados con los valores estimados. La forma algebraica de esta medida es:

$$
E P C=\sum_{j=1}^{n}\left(D j-D^{\prime} j\right)^{2}
$$

donde $D j$ denota los valores observados en los puntos de atracción y $D^{\prime} \mathbf{j}$ los valores estimados, en ambos casos para $j=1,2, \ldots, n$.

A partir de las ecuaciones (2) a (6), observamos que el calibramiento de los modelos se efectúa a partir de los valores del EPC y del parámetro a. Es decir, en el ajuste de los modelos para predecir $D j$, es conocido el valor de las constantes $K, O i, A j$. Sólo la función de distancia $f$ [dij] es desconocida dado que su valor depende del parámetro $a$. 
El calibramiento de los modelos consiste, entonces, en encontrar el parámetro a de la función de distancia que minimice el valor del EPC. Una vez encontrado el modelo más adecuado de la interacción entre $\mathrm{Oi}$ y $\mathrm{Dj}$, su uso predictivo mantiene las distancias, el valor del parámetro a de la función de distancia y la atractividad de los destinos para modelar la interacción en términos de la PEA desocupada.

El resultado final del uso del modelo gravitatorio con restricción en los orígenes es conocer $\mathrm{Dj}$, la distribución en cada punto de destino del total de viajes generados en los puntos de producción.

Modelo gravitatorio con restricciones en los orígenes y los destinos

A partir de los resultados del ajuste y uso predictivo del modelo gravitatorio con restricción en los orígenes, contamos con la distribución marginal de una matriz de viajes. Con base en esta información, se pueden definir las magnitudes específicas de viajes generados en cada uno de los puntos de producción hacia cada uno de los puntos de atracción. Éste es el tipo de problema específico que trata el modelo gravitatorio con dos restricciones, en los orígenes y en los destinos. Las siguientes ecuaciones muestran las restricciones que debe satisfacer un modelo doblemente restringido:

$$
\begin{aligned}
& \sum_{i=1}^{n} T i j=O i \\
& \sum_{i=j}^{m} T i j=D j
\end{aligned}
$$

Los datos generados por el ajuste del modelo con una restricción permiten satisfacer ambas condiciones. La distribución de viajes de cada punto de origen i a cada punto de atracción j se expresa algebraicamente como:

$$
\mathrm{Tij}=\text { ki lj Oi Dj f(dij) }
$$

Es decir, cada Tij, que expresa los viajes de $\mathrm{i}$ a $\mathrm{j}$, depende de $O \mathrm{i}, \mathrm{Dj}$, de los parámetros $\mathrm{ki}$ y $\mathrm{lj}$, asociados a $\mathrm{Oi}$ y $D \mathrm{j}$, respectivamente, así como de la función de distancia $f($ dij). En nuestro caso, el ajuste del modelo con una restricción permitió encontrar la función de distancia y su parámetro a más adecuado. De esta manera, 
para estimar los valores de Tij se requiere conocer los parámetros ki y lj, Ilamados de factores de balance. Estos parámetros no pueden estimarse directamente dado que:

$$
\begin{aligned}
& K i=\frac{1}{\sum_{i=1}^{n} l j D j f(d i j)} \\
& l j=\frac{1}{\sum_{i=1}^{m} k i \text { Oi } f(d i j)}
\end{aligned}
$$

Se utiliza, por lo tanto, un algoritmo iterativo para encontrar los valores de los parámetros. El algoritmo parte de asignar un valor inicial al parámetro ki en la ecuación (11). ${ }^{3} A$ partir del valor obtenido de $\mathbf{l j}$, se calcula la ki respectiva al par de puntos $i$, $j$, en consideración. El algoritmo continúa hasta que la diferencia en los valores encontrados no rebasa, de una iteración a otra, un valor de convergencia definido de antemano. Obtenidos los parámetros, se estiman los flujos Tij para cada par de puntos de producción y de atracción.

\section{Formulación de los modelos}

La hipótesis señalada en la introducción orienta la formulación de los modelos. En ellos se identifica con el subíndice i a las localidades de producción de viajes y con j a las de atracción. Oi representa a la PEA total de las localidades de origen y $D j$ de las localidades de destino. El factor de atractividad $A j$ es expresado como el recíproco del porcentaje de población desocupada en relación con la PEA, en cada lugar de destino. Con esto, suponemos que la atractividad que presenta cada punto de destino $j$ es inversamente proporcional al porcentaje de PEA desocupada. Esto indicaría que a menor porcentaje de desempleo, mayor atractividad.

\section{Consideraciones acerca de los datos del modelo}

La PEA es la expresión más general de la actividad económica. Como dato agregado no diferencia entre sectores de actividad, ocu-

\footnotetext{
${ }^{3}$ De hecho, el algoritmo puede igualmente iniciar asignando valores a lj.
} 
paciones principales o posiciones en el trabajo. Evidentemente se podria echar mano de otras informaciones sobre actividad económica tales como las referidas a producción o consumo. Sin embargo, para el propósito ilustrativo de la aplicación de modelos gravitatorios para el análisis de las interacciones entre mercados laborales locales a nivel estatal, consideramos que la PEA, por su carácter general, es un indicador adecuado de la "masa" de las localidades. ${ }^{4}$

Otra observación pertinente es en relación con el uso de las proporciones de PEA desocupada como variable de aproximación para el ajuste del modelo gravitatorio con restricción en los orígenes. Es sabido que generalmente es un dato subestimado, dado que la mayoría de las personas declaran tener alguna actividad. Consideramos, para propósitos operacionales, que el sobrerregistro de actividad es homogéneo en las localidades en observación. Con este supuesto, y por las características del modelaje, se subsanan las limitaciones que imponen consideraciones como la señalada. Por otra parte, el porcentaje de PEA ocupada podría hacer las veces del recíproco del porcentaje de desocupados. Sin embargo, es más interesante, como premisa analítica, considerar la atractividad como función inversa del porcentaje de desocupación. Es decir, es más atractivo un punto donde la desocupación sea menor. El cuadro 1 muestra que el porcentaje de la PEA estatal desocupada es menor en el caso de las localidades consideradas de destino al tiempo que la PEA ocupada es mayor en las localidades consideradas como de origen. Lo anterior ilustra el razonamiento para considerar a la PEA desocupada para definir la atractividad de las localizaciones, en vez de la PEA ocupada. ${ }^{5}$

${ }^{4}$ El INEGI define la Población Económicamente Activa como: "Total de personas de 12 años y más que en la semana de referencia se encontraban ocupadas o desocupadas" (INEGI, 1991: 166).

${ }^{5}$ El INEGI define como población ocupada: "Total de personas de 12 años y más que realizaron cualquier actividad económica en la semana de referencia, a cambio de un sueldo, salario, jornal u otro tipo de pago en dinero o especie".

"Incluye, además, a las personas que tenían trabajo pero no trabajaron en la semana de referencia por alguna causa temporal (vacaciones, licencia, enfermedad, mal tiempo, huelga, o estaban en espera de iniciar o continuar con las labores agrícolas)".

"Incluye también a las personas que ayudaron en el predio, fábrica, tienda o taller de algún familiar sin recibir sueldo de ninguna especie, y a los aprendices 0 ayudantes que trabajaron sin remuneración" (INEGI, 1991: 166).

La definición de población desocupada que el INEGI da, es: "Total de personas de 12 años y más que en la semana de referencia no tenían trabajo, pero lo buscaron activamente". 
CUADRO 1

PEA total, ocupada y desocupada por tipo de localidades, porcentajes

\begin{tabular}{lccc}
\hline & PEA & & \\
\cline { 2 - 4 } Localidades & Total & Ocupada & Desocupada \\
\hline De producción & 77.77 & 75.88 & 71.94 \\
De atracción & 24.23 & 24.12 & 28.06 \\
& 100.00 & 100.00 & 100.00 \\
Total & 171674 & 167016 & 4658 \\
\hline
\end{tabular}

Fuente: elaboración propia con base en las informaciones del cuadro 2.

En cuanto a las distancias, en el caso de no contar con las coordenadas de las localidades, se podría alimentar el modelo con distancias definidas por otros procedimientos. Adicionalmente, ot ro tipo de unidades de medición de distancia pueden ser utilizadas (tiempo, costo). Cada tipo de unidad de medición implica consideraciones particulares. El uso de distancias a partir de las coordenadas proporcionadas por la proyección Universal Tranversa de Mercator (coordenadas UTM) es, en ese sentido, "neutro". Para la aplicación del modelo, incluso tomando en cuenta las distancias, es irrelevante considerar distancias carreteras. Este tipo de información podría considerarse más adecuado. Sin embargo, supondría, al igual que las distancias estimadas a partir de coordenadas UTM, que ésos constituyen los únicos recorridos posibles entre localidades. Este tipo de modelaje, en red, corresponde más a problemas de localización de instalaciones que a estimaciones de flujos restringidos, preocupación que anima a este trabajo.

\section{Procedimiento de trabajo}

El cuadro 2 presenta las informaciones pertinentes para la formulación del modelo. El factor de atractividad $A j$ es calculado como el recíproco del porcentaje de la PEA desocupada en la PEA total.

El procedimiento de modelaje es el siguiente: primero se calculan las distancias dij entre puntos de producción y de atracción de viajes, con base èn el teorema de Pitágoras, a partir de las coordenadas UTM.

Estas distancias se consignan en el cuadro 3.

\footnotetext{
"Incluye a los buscadores de trabajo que ya habian trabajado como a los que buscaron trabajo por primera vez" (INEGI, 1992: 756). La semana de referencia de la información censal es la que abarca del 5 al 11 de marzo de 1990.
} 


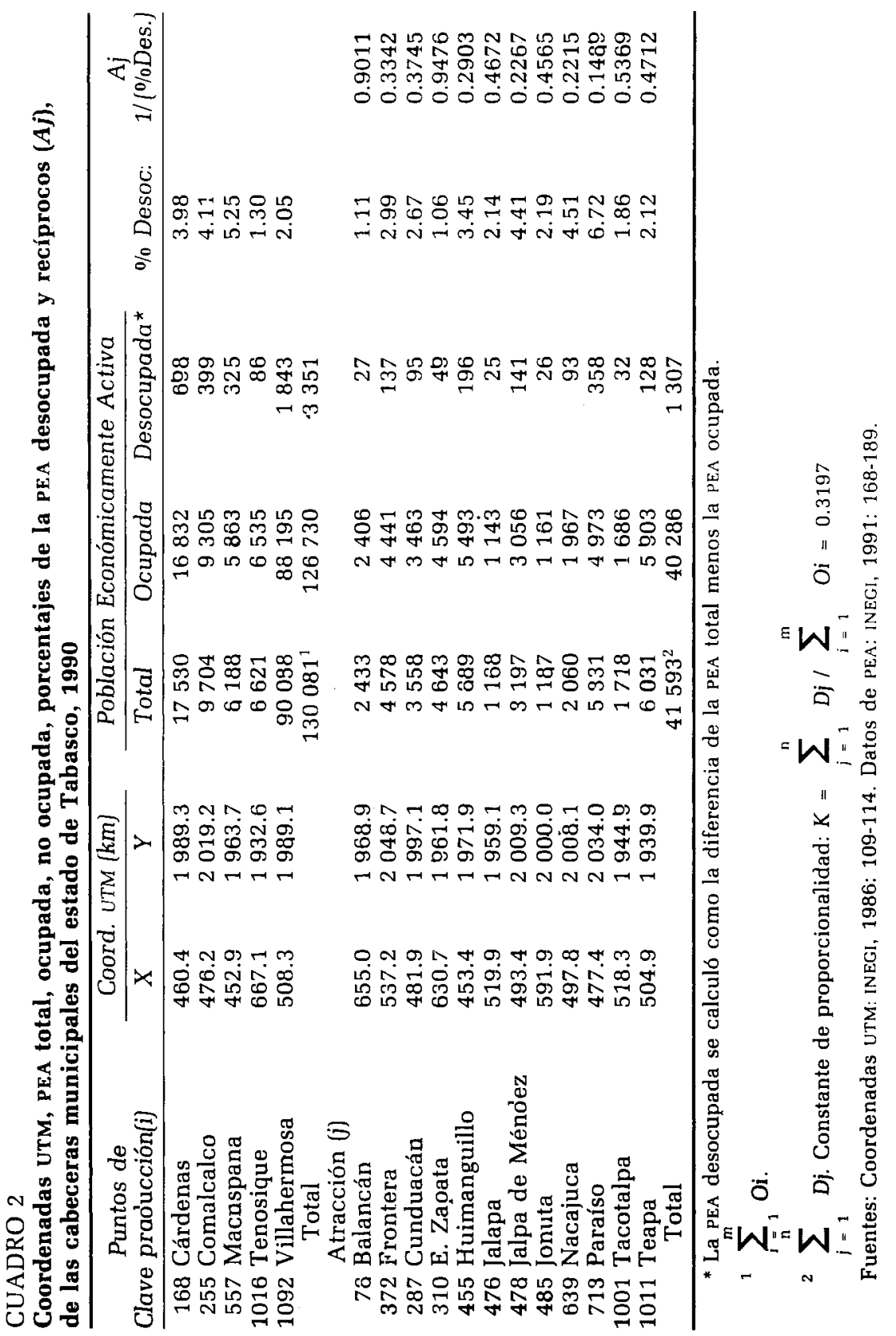




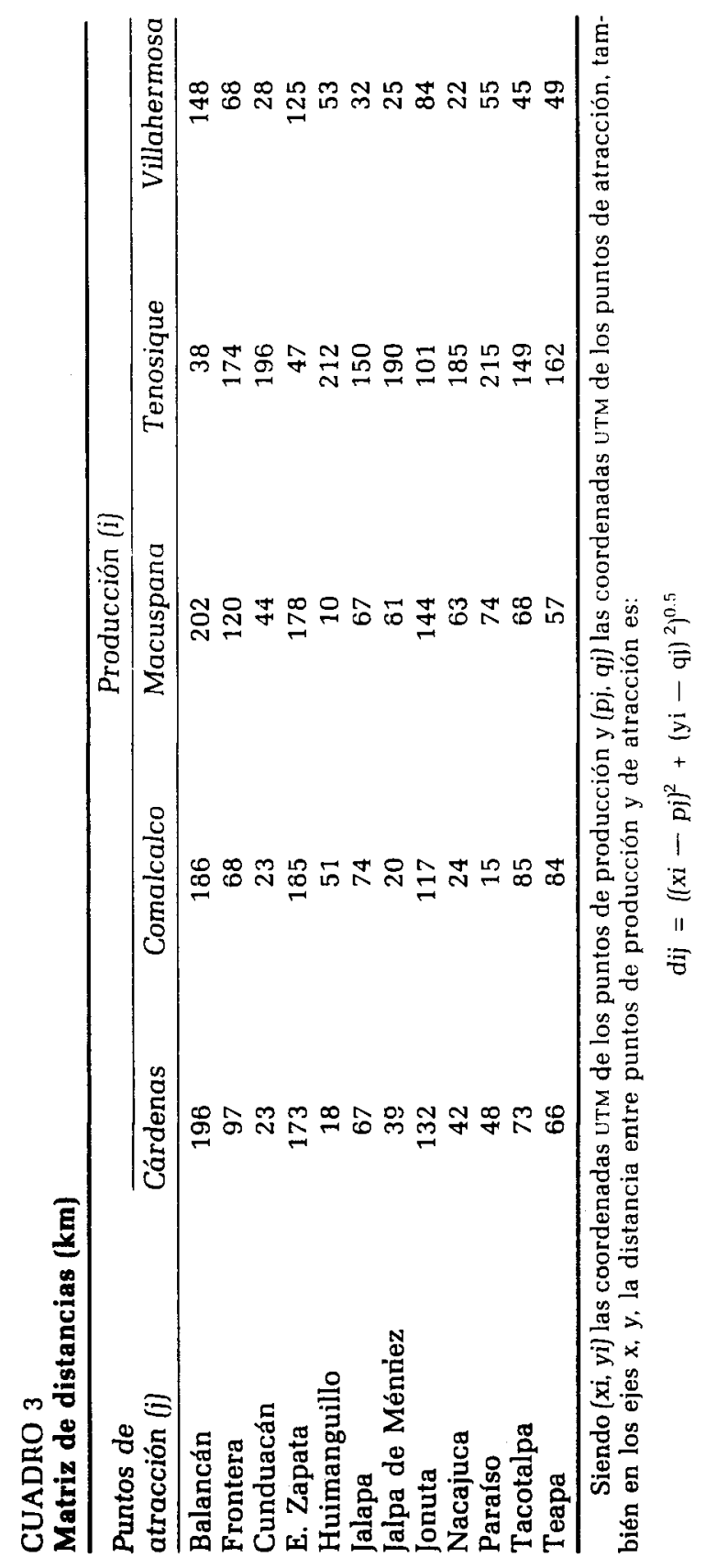




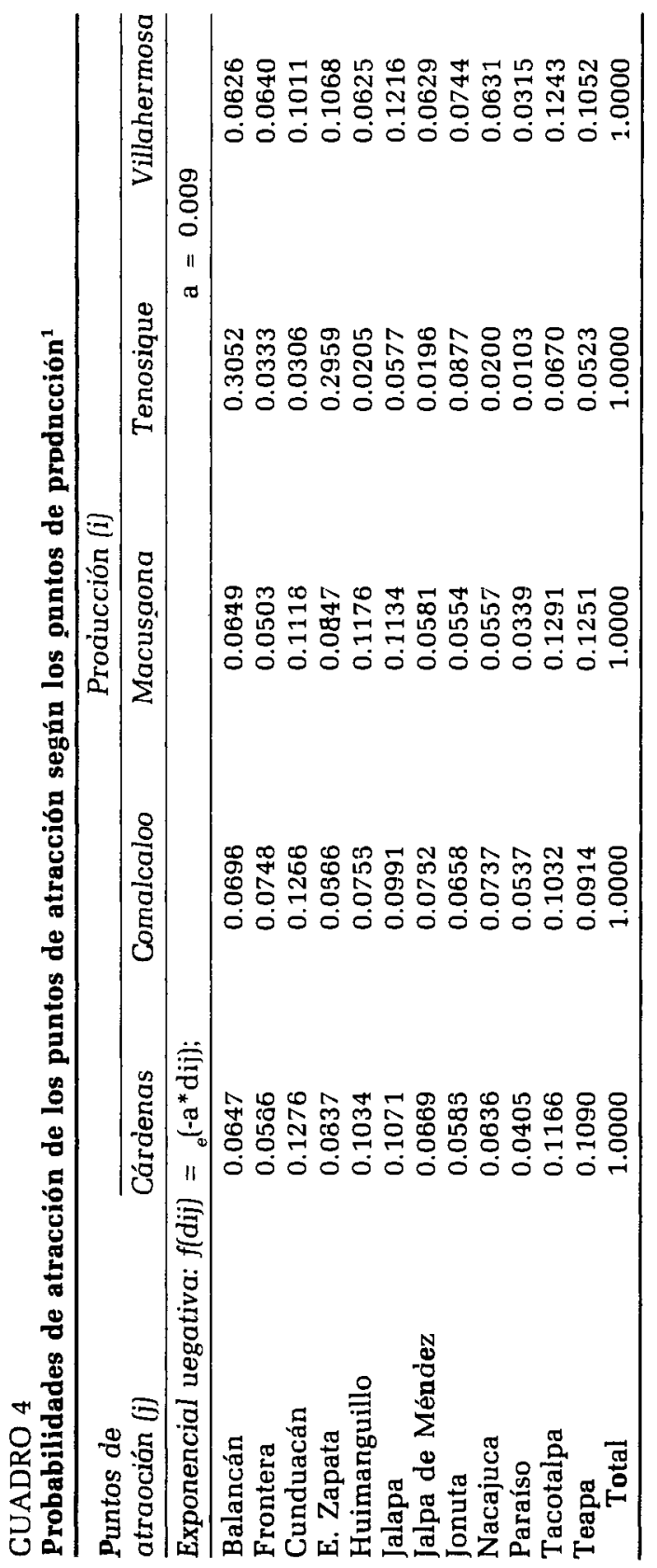




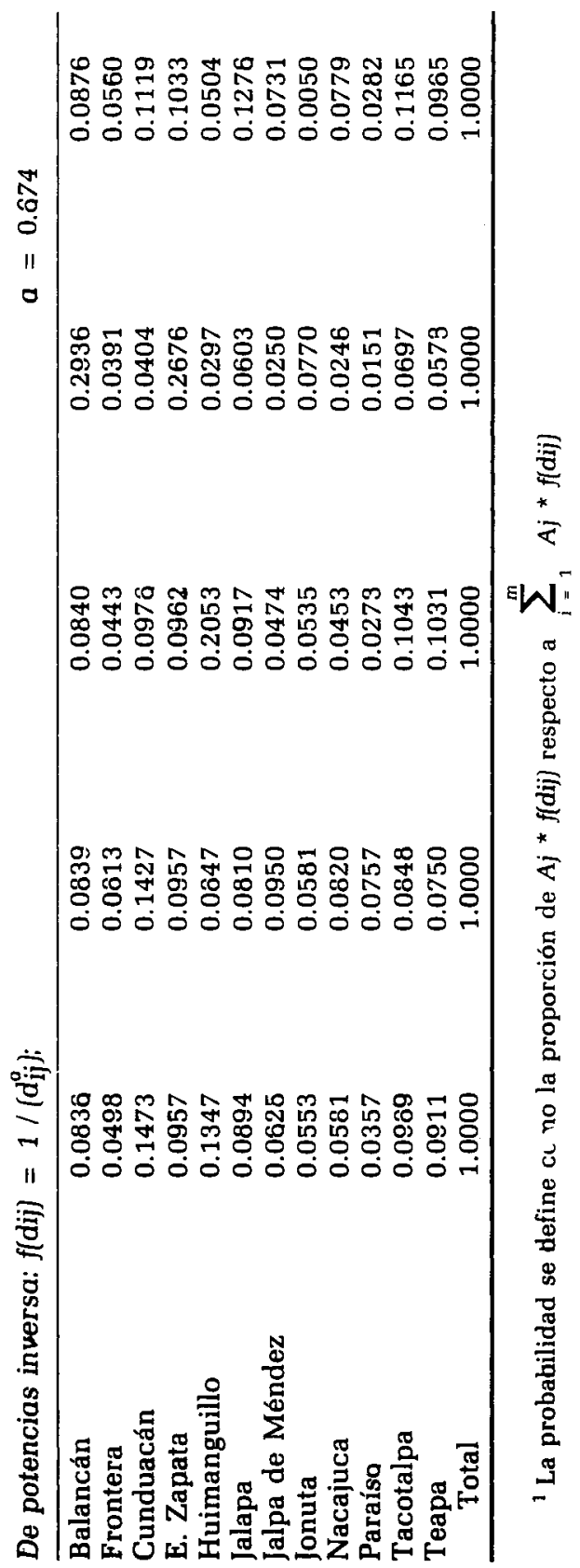




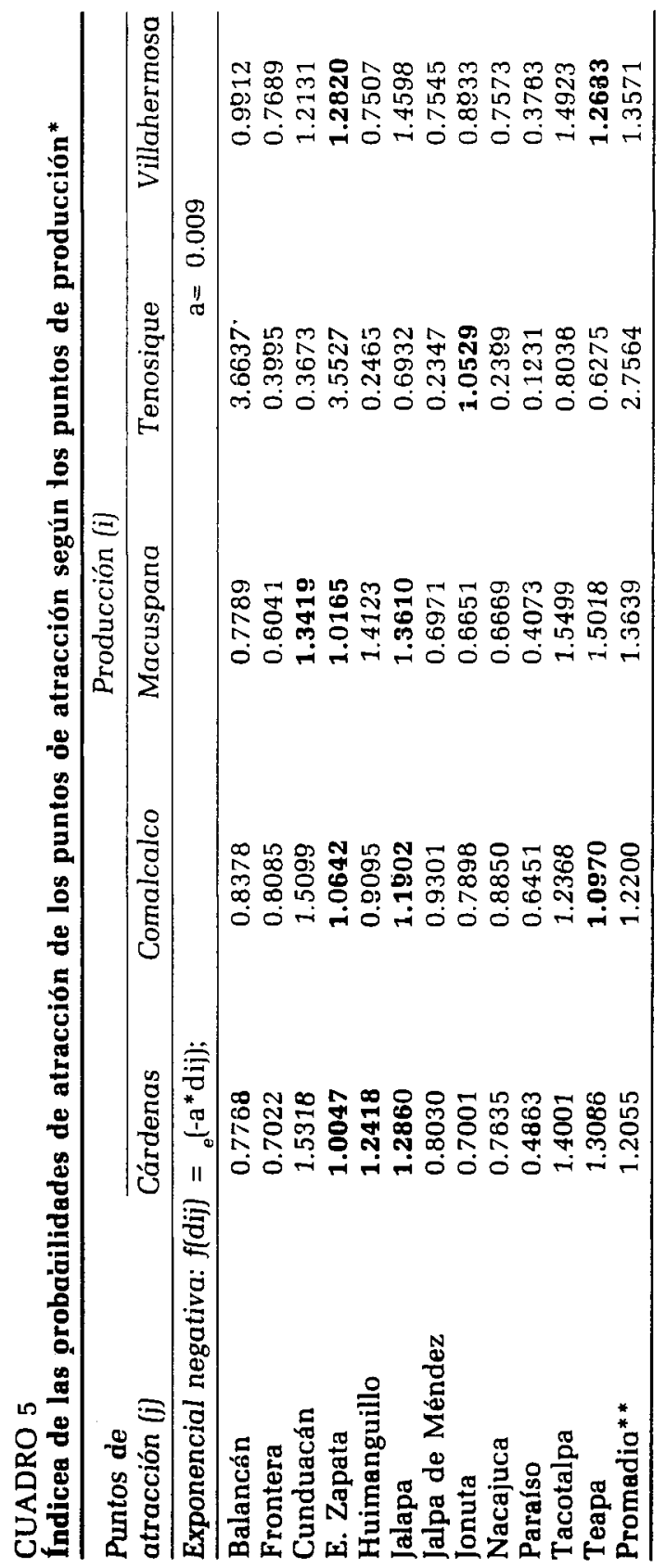




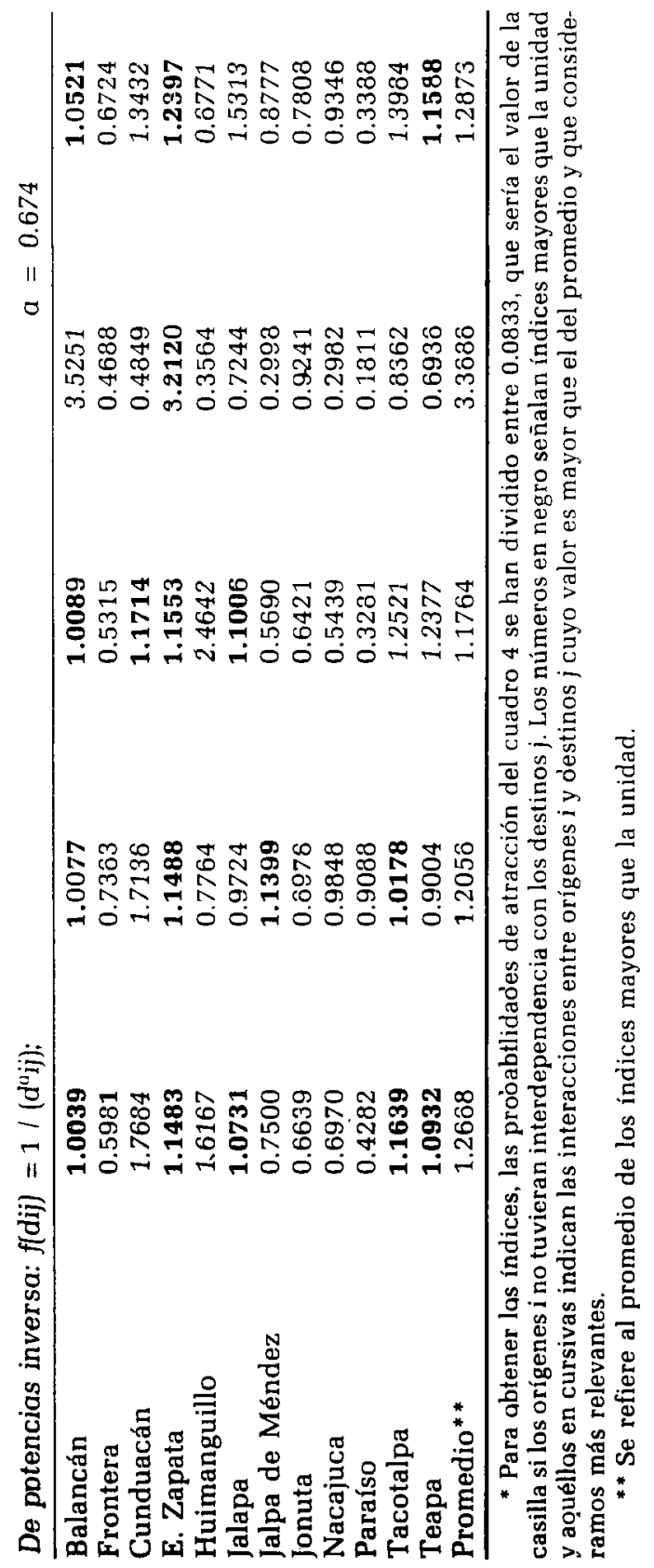




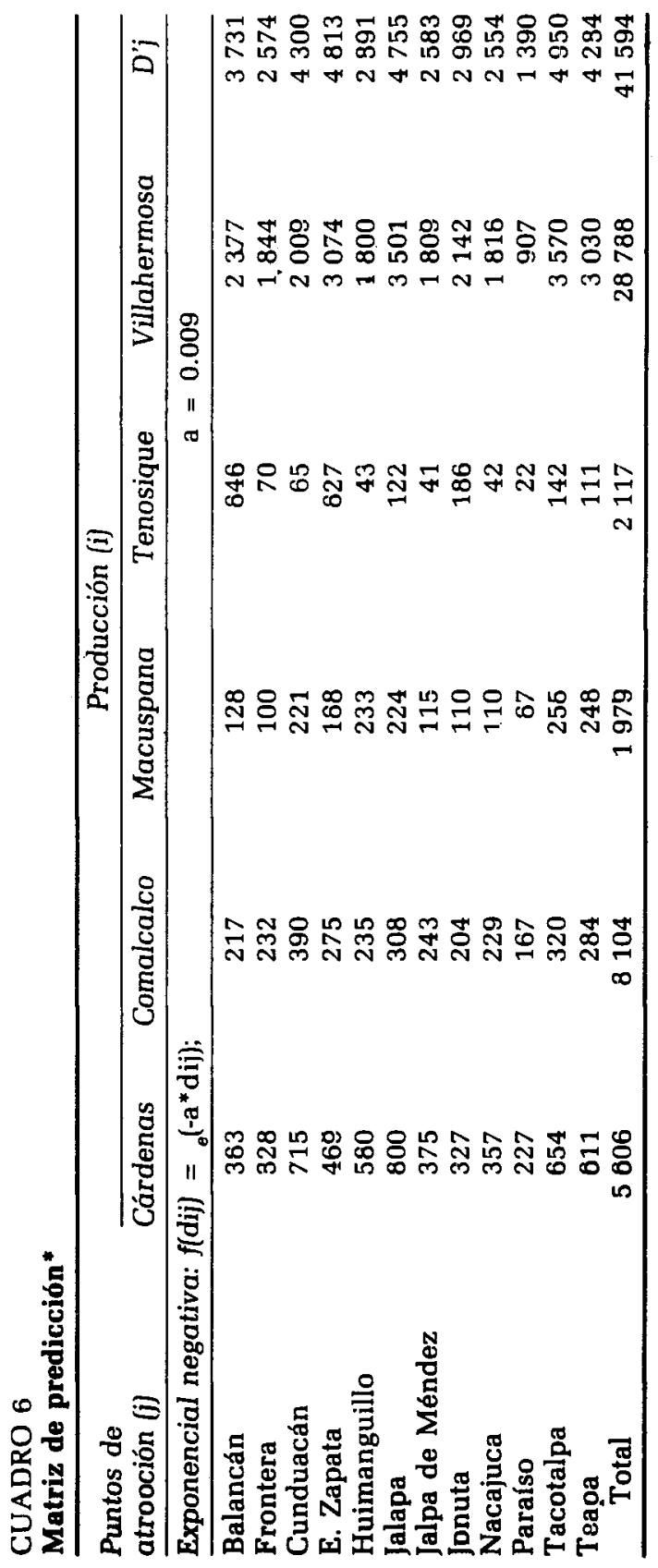




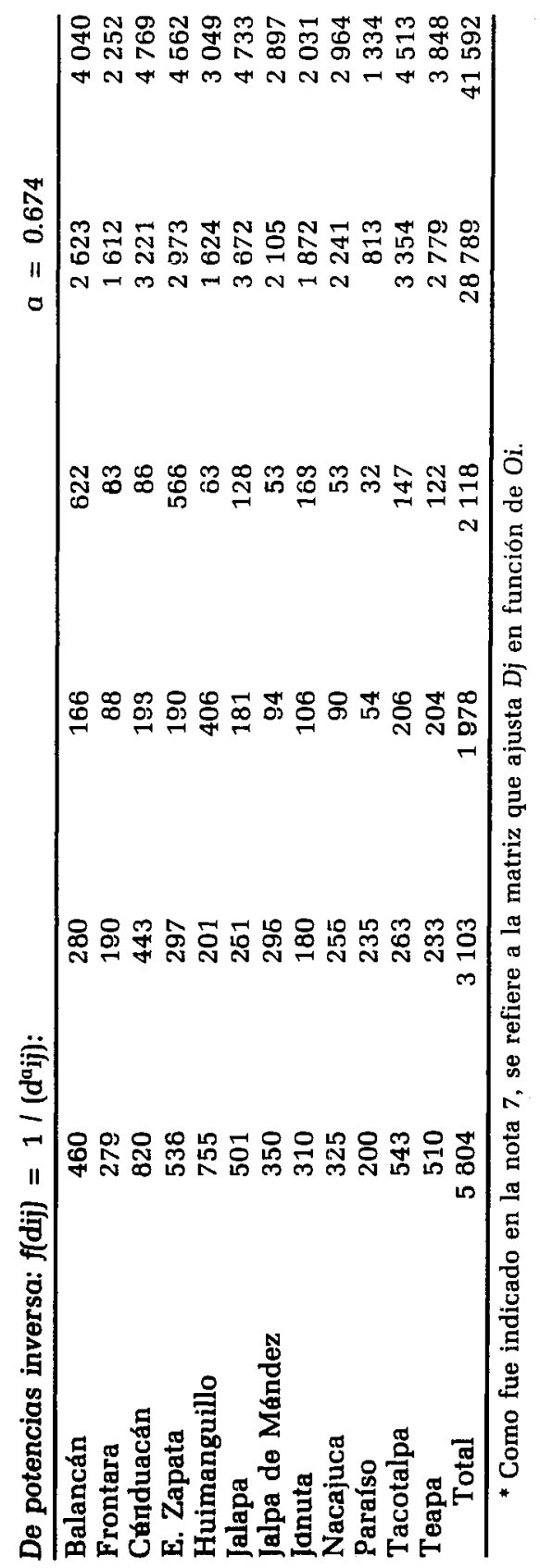


Después se calcula el valor de la función de distancia para cada distancia dij, con un parámetro arbitrariamente escogido. En este trabajo se aplican tanto la función de distancia exponencial negativa como la inversa de potencias para el posterior calibramiento y selección del modelo más adecuado. Los resultados que se presentan corresponden a los valores del parámetro a que permiten menores valores del EPC. El análisis de resultados se basa en un modelo con función de distancia exponencial negativa con parámetro $a=0.009$.

A continuación, se obtiene el producto de los factores de atractividad $A j$ multiplicados por los valores de la función de distancia para la correspondiente $j$, y la sumatoria para cada punto de producción de viajes, $i$. A partir de los datos anteriores, los productos son considerados como proporciones de las sumatorias, que permiten la interpretación probabilística indicada antes.

Con base en estos datos, se construyen los índices de las probabilidades como el cociente del valor de la probabilidad específica de la interacción entre cada punto de origen i y cada punto de destino j, entre la probabilidad de que los viajes producidos en cada i se distribuyeran uniformemente entre cada destino j. Esto constituye la base principal de nuestro análisis de flujos. Se considera que los índices mayores que uno, expresan una atractividad de los puntos de destino $j$, mayor a que si los viajes producidos en i se distribuyeran uniformemente entre los posibles destinos, y representan las principales interacciones.

Con los datos generados, y la constante de proporcionalidad calculada de la manera antes expuesta, se obtiene la matriz conocida como de "predicción”, que constituye el resultado final del ajuste del modelo. ${ }^{6}$ Esta matriz se presenta como cuadro 6.

El cuadro 7 presenta el calibramiento del modelo a partir de los diferentes resultados obtenidos del EPC en función de diferentes valores otorgados al parámetro $a$. Un valor de $a$ igual a cero, implica el error que se generaría si solamente se consideraran los factores de atractividad. ${ }^{7}$ Dada esa característica, representa un "techo" del error. Se efectúa una aproximación a partir del ensa-

\footnotetext{
${ }^{6}$ A pesar de ser llamada de predicción, esta matriz es, en primera instancia, de resultados del ajuste de los modelos. El carácter "predictivo" radica en que, una vez elaborado y seleccionado el modelo, sus parámetros pueden ser utilizados para propósitos prospectivos.

${ }^{7}$ En las funciones de distancia, al asignar un valor de 0 al parámetro a se obtiene la unidad como valor. En el caso de la forma exponencial negativa de la función de distancia, esto se explica porque $\mathrm{e}^{-a d i j}=\mathrm{e}^{\mathrm{o}}=1$. En el caso de la función de potencias inversa $1 / \mathrm{d}_{\mathrm{ji}}^{\mathrm{g}}=1 / 1=1$. Siendo $f(\mathrm{dij})$ igual a la unidad, los productos $A j$ * $f(d i j)$, expresarían sólo el valor de $A j$.
} 
CUADRO 7

Evaluación del error promedio cuadrado de las funciones de distancia en función del parámetro a. EPC $=\mathrm{f}(\mathbf{a})^{*}$

\begin{tabular}{|c|c|c|c|}
\hline \multicolumn{4}{|c|}{ Funciones de distancia } \\
\hline \multicolumn{2}{|c|}{ Exponencial negativa } & \multicolumn{2}{|c|}{ Potencias inversa } \\
\hline$a$ & EPC & $a$ & $E P C$ \\
\hline 0.000 & 7238846 & 0.00 & 7238846 \\
\hline 0.005 & 5389567 & 0.10 & 6611755 \\
\hline 0.010 & 4981217 & 0.20 & 6098141 \\
\hline 0.015 & 5340735 & 0.30 & 5692738 \\
\hline \multirow[t]{2}{*}{0.020} & 6038120 & 0.40 & 5392584 \\
\hline & & 0.50 & 5191133 \\
\hline 0.008 & 5017817 & 0.60 & 5083745 \\
\hline \multirow[t]{2}{*}{0.009} & 4981127 & 0.70 & 5060130 \\
\hline & & 0.80 & 5115581 \\
\hline \multirow[t]{14}{*}{0.011} & 5008188 & 0.90 & 5236011 \\
\hline & & 0.61 & 5077565 \\
\hline & & 0.62 & 5072946 \\
\hline & & 0.63 & 5068587 \\
\hline & & 0.64 & 5065072 \\
\hline & & 0.65 & 5063221 \\
\hline & & 0.66 & 5059982 \\
\hline & & 0.67 & 5059397 \\
\hline & & 0.68 & 5059516 \\
\hline & & 0.671 & 5058736 \\
\hline & & 0.672 & 5058505 \\
\hline & & 0.673 & 5058127 \\
\hline & & 0.674 & 5057542 \\
\hline & & 0.675 & 5058080 \\
\hline
\end{tabular}

* Los números en negro indican el menor EPC: alcanzado en cada aproximación a partir de considerar 1,2 y 3 decimales.

yo de una serie de valores ascendentes del parámetro a hasta encontrar el límite inferior de la función $E P C=f(a)$, en milésimas, que consideramos satisfactorio. Para el ajuste del modelo utilizando la función de distancias exponencial negativa, el menor valor encontrado para EPC es de 4981127 para un valor del parámetro $a$ de 0.009. El EPC mínimo, ajustado en milésimas, para la función de distancia de potencias inversa, es de 5057542 para un valor del parámetro a de $0.674 .^{8} \mathrm{El}$ modelo que consideramos más ade-

${ }^{8}$ La magnitud del error tiene que ver con el tamaño de los propios datos. Asi, por ejemplo, una diferencia de 1000 entre los valores observados y los estimados genera un error de 1000000 . Estas diferencias se suavizan al dividir entre el número total de puntos de atracción. Sin embargo, la magnitud del resultado de EPC será grande. 
cuado, en función del error que arroja, es el que se sirve de la función de distancia exponencial negativa con un parámetro $a=0.009$. Las interpretaciones de resultados se basan en este modelo ajustado.

En la gráfica 1 puede apreciarse que, según se incrementa la distancia, la forma exponencial negativa reduce de manera más drástica el valor de la función de distancia que en el caso de la forma de potencias inversa. Dado que el mejor ajuste encontrado se consiguió utilizando la forma exponencial negativa, el efecto de la distancia en la formulación del modelo cobra mayor relevancia.

\section{GRÁFICA 1}

Interacción de mercados laborales

Tabasco, 1990

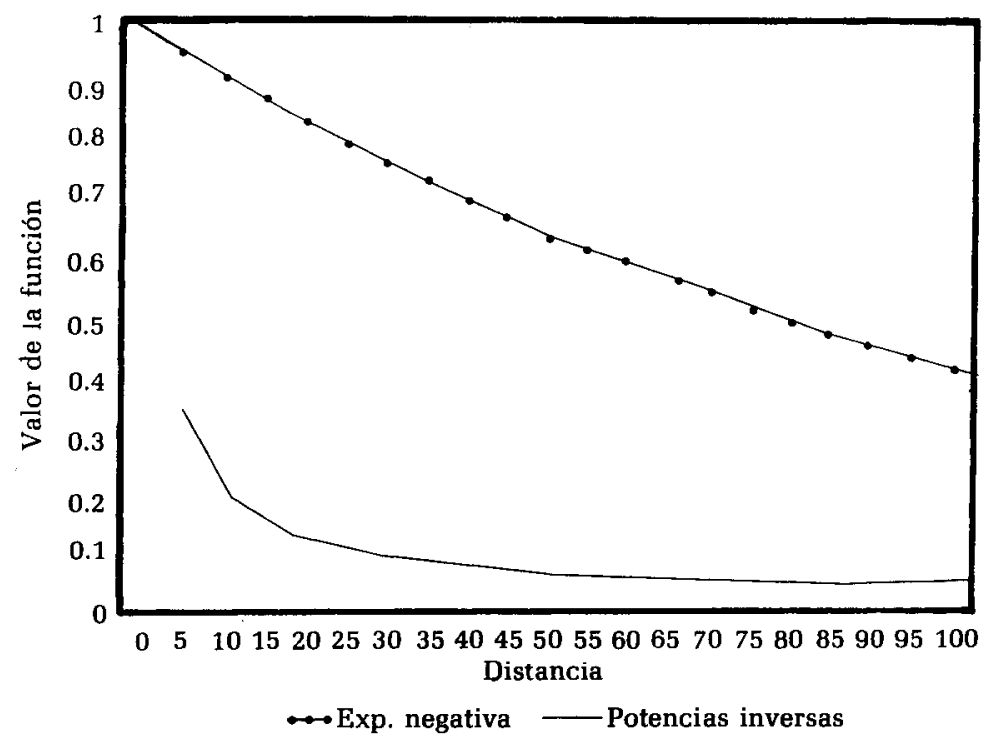

Definido el modelo que mejor ajusta los valores observados, se genera un modelo predictivo. Este modelo, utilizando la función de distancia y el parámetro a del modelo ajustado, predice las magnitudes de los destinos que podrían esperarse en caso de reubicarse la PEA desocupada de las cinco principales localidades en las restantes. A partir de conocer la distribución marginal de la matriz de predicción (los orígenes según los puntos de producción de viajes y los destinos según puntos de atracción), se efectúa el modelaje con dos restricciones para estimar los flujos Tij, resultado final del trabajo.

El cuadro 8 muestra los valores de los parámetros ki y lj para 
las dos funciones de distancia, correspondientes a los valores del parámetro a encontrado en el ajuste del modelo con una restricción. A partir de conocer los parámetros que modelan la relación entre puntos de origen y puntos de destino, se puede realizar la predicción de viajes.

Esta predicción, mostrada en el cuadro 9, toma en cuenta los niveles absolutos de PEA desocupada en los puntos de origen y la distribuye entre los de destino, según el modelo ajustado. Por último, el cuadro 10 muestra la distribución porcentual de viajes.

\section{Análisis de los modelos}

Como fue señalado, los resultados que se analizan corresponden al modelo gravitatorio con una restricción que mejor ajustó los datos, o sea, utilizando la función de distancia exponencial negativa con un parámetro a de 0.009 . El cuadro 4 expresa el cociente de la atractividad multiplicado por la función de distancia, dividido esto entre la sumatoria de estos valores para todos los puntos de origen. La interpretación probabilística ilustra cómo se distribuye, entre los puntos de destino, la probabilidad de que los viajes generados en los puntos de origen i tengan tales destinos j. Siendo doce los destinos posibles, si los viajes de cada punto de origen se distribuyeran indistintamente entre los destinos, la probabilidad sería igual a 1/12 o sea, 0.0833 . Consideramos que las principales interacciones son aquellas en las que la probabilidad es mayor a este valor. Aún siendo la atractividad de todos los puntos de destino igual, el cociente referido sería diferente para cada par de puntos de origen y destino en la medida en que la función de distancia es calculada para cada uno de ellos.

Para contar con un indicador preciso que relativice y permita la comparabilidad de las probabilidades de manera más clara, se generó un índice que se presenta en el cuadro 5 . Éste se construye a partir de dividir las probabilidades entre 0.0833 , lo cual permite apreciar la magnitud del distanciamiento de las probabilidades de una situación de distribución homogénea. ${ }^{9}$ De esta manera, un valor menor que uno, expresa que la probabilidad de esta interacción es menor que la de la distribución homogénea, un valor de uno, expresa que la probabilidad es la misma de la distribución

\footnotetext{
${ }^{9}$ El razonamiento de esta evaluación es similar a la prueba de ji-cuadrado. Un f́ndice mayor a la unidad estaría expresando una magnitud mayor del valor estimado en relación con el que se esperaría si la distribución de viajes fuera homogénea, rechazando así la hipótesis de independencia.
} 


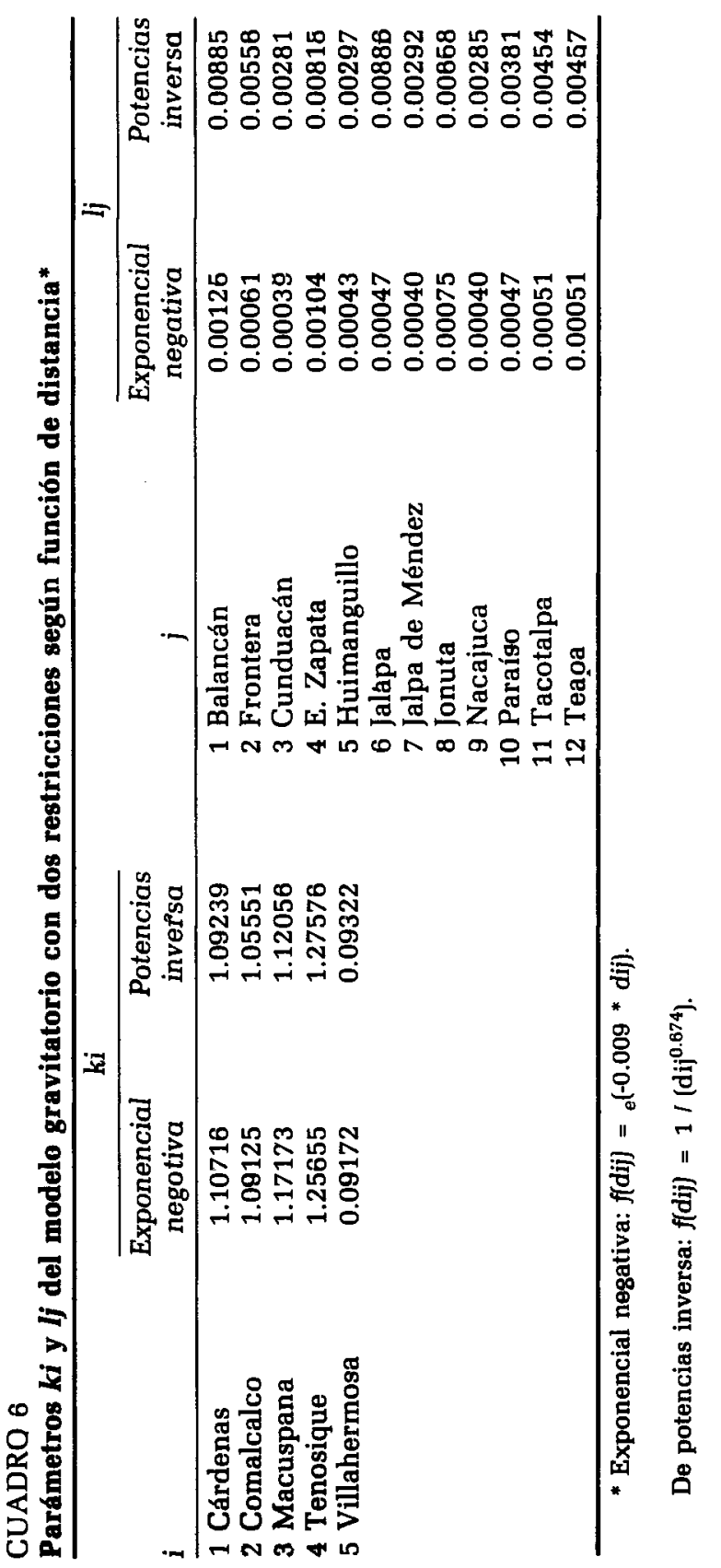


homogénea y un valor mayor de uno, indica que la probabilidad es may or que la de distribución homogénea. Por lo tanto, las magnitudes de más de uno, son nuestro centro de atención en la medida en que expresan la mayor interdependencia entre puntos de origen y puntos de destino.

Análisis de las interacciones según el modelo con restricción en los orígenes

El análisis de resultados se basa en los índices de las probabilidades presentados en el cuadro 5 . En él se puede observar, en primer lugar, que las localidades de Frontera, Jalpa de Méndez, Nacajuca y Paraíso no muestran en ningún caso índices mayores que la unidad. Cunduacán, Tacotalpa y Teapa presentan índices mayores que la unidad, excepto en el caso de su interacción con Tenosique. La principal interacción de Cunduacán es con Cárdenas y de Tacotalpa y Teapa, con Macuspana. Huimanguillo y Jalapa muestran índices mayores que uno, en su interacción con Cárdenas y Macuspana, siendo las principales interacciones de ambas localidades con esta última. Balancán y Jonuta presentan índices mayores que la unidad en su interacción con Tenosique, resaltando el índice de la interacción de Balancán con Tenosique. Emiliano Zapata presenta índices mayores que la unidad en su interacción con todos los puntos de producción, especialmente con Tenosique, sin soslayar la interacción con Villahermosa. Estas interacciones se ilustran en el mapa 1.

Tomando como referencia el promedio de los índices según cada punto de producción i, consideramos como las interacciones más relevantes, aquellas que muestran un valor superior a éste. Bajo este criterio, las principales interacciones de Cárdenas son con Cunduacán, Tacotalpa y Teạpa; de Comalcalco, con Cunduacán y Tacotalpa; de Macuspana, con Huimanguillo, Tacotalpa y Teapa; de Tenosique, con Balancán y Emiliano Zapata, y de Villahermosa, con Jalapa y Tacotalpa. El mapa 2 muestra estas interacciones.

Como puede inferirse de estos resultados, en'el caso de Frontera, Jalpa de Méndez, Nacajuca y Paraíso se trata de localidades que no constituyen alternativas de ampliación de mercados laborales respecto de aquellos de las principales localidades, consideradas como puntos de origen. Por su parte, Tacotalpa tendría un papel fundamental en ese sentido. Distinguimos una fuerte interacción de Tenosique con Balancán y con Emiliano Zapata. Esta constatación permite inferir que la zona sur del estado puede con- 


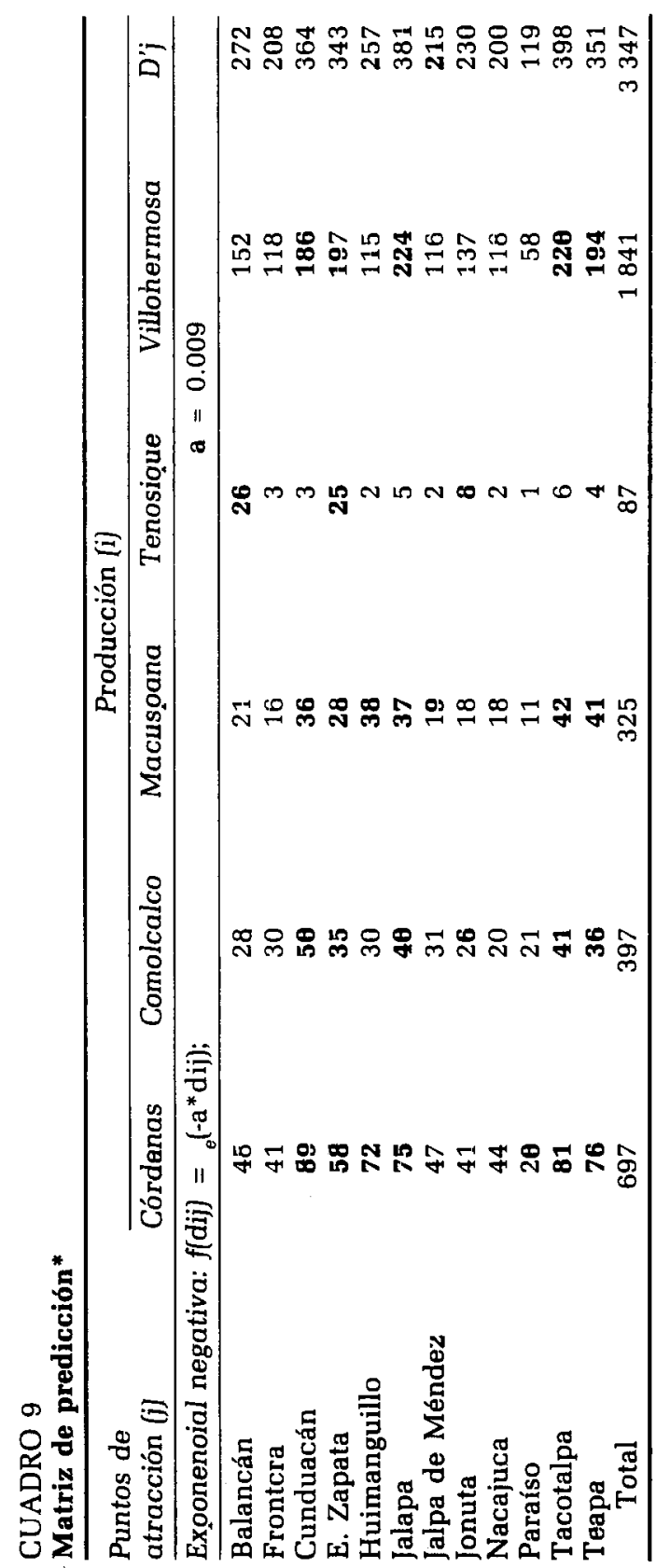




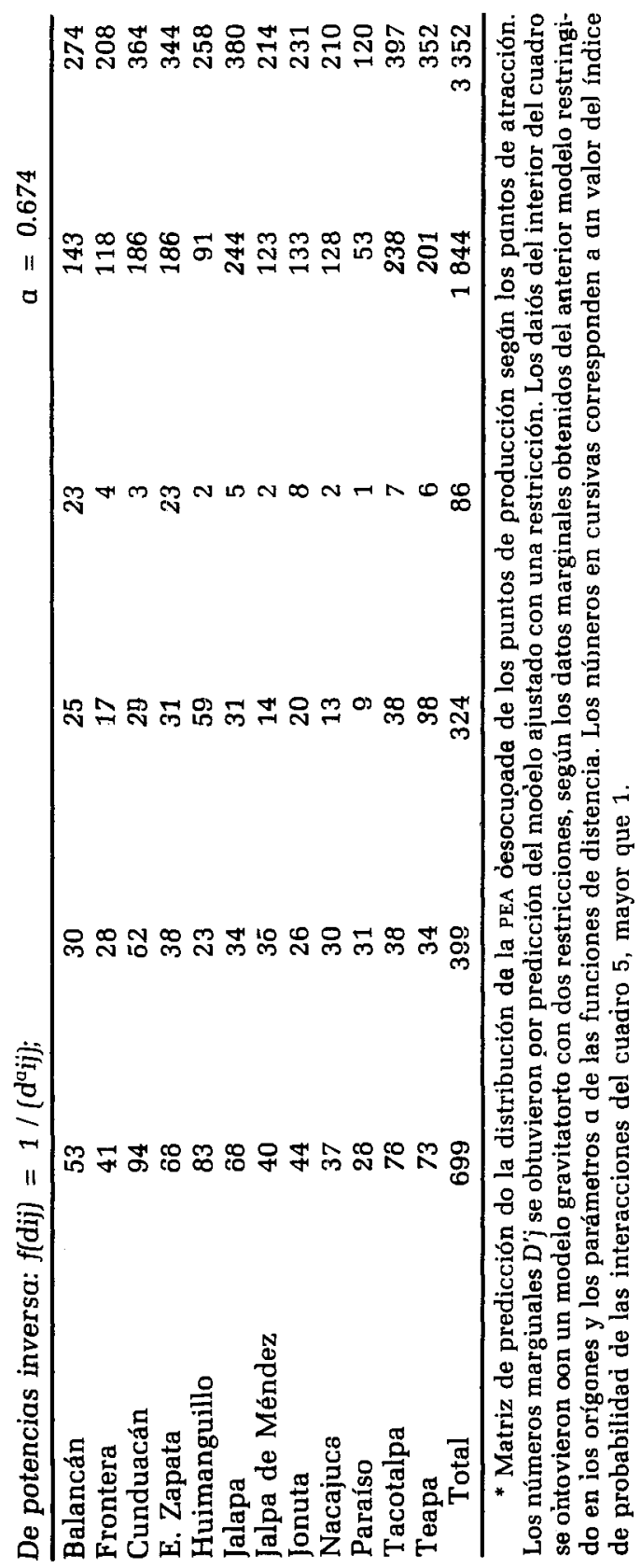




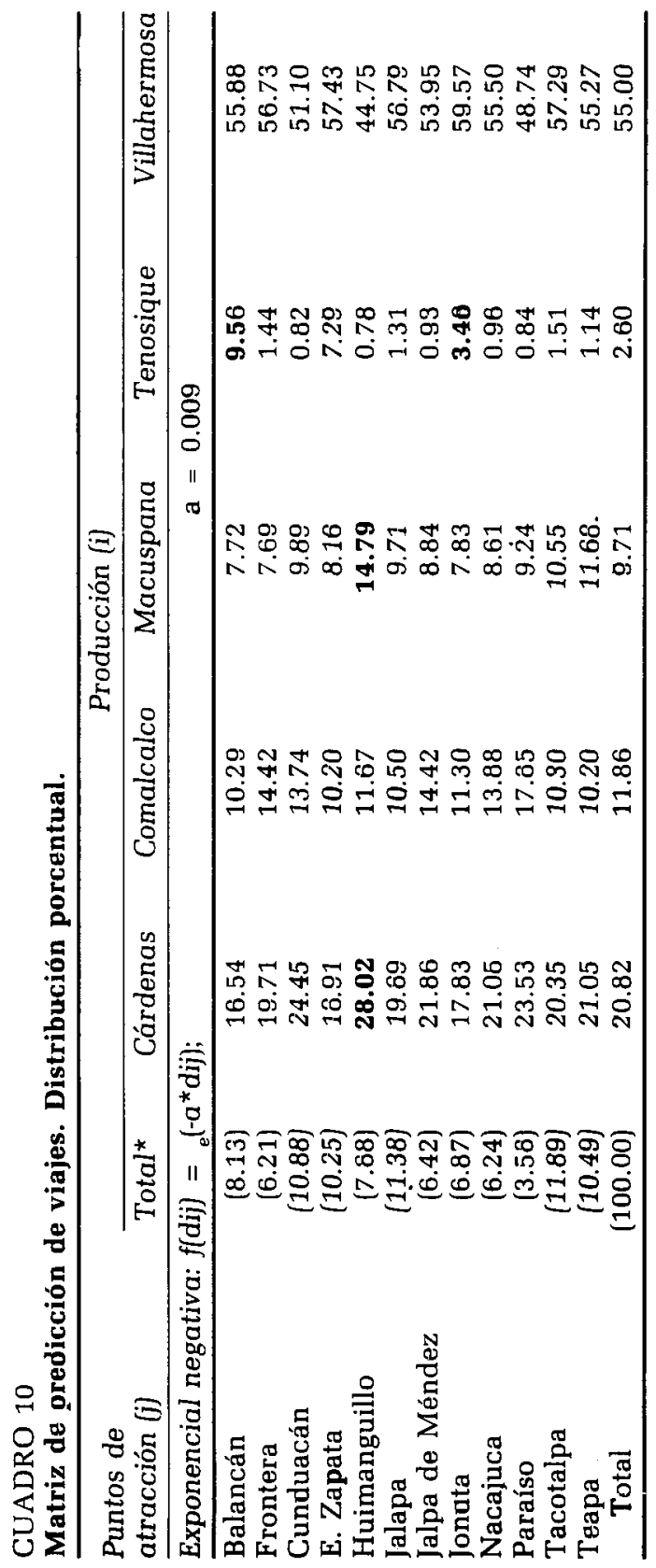




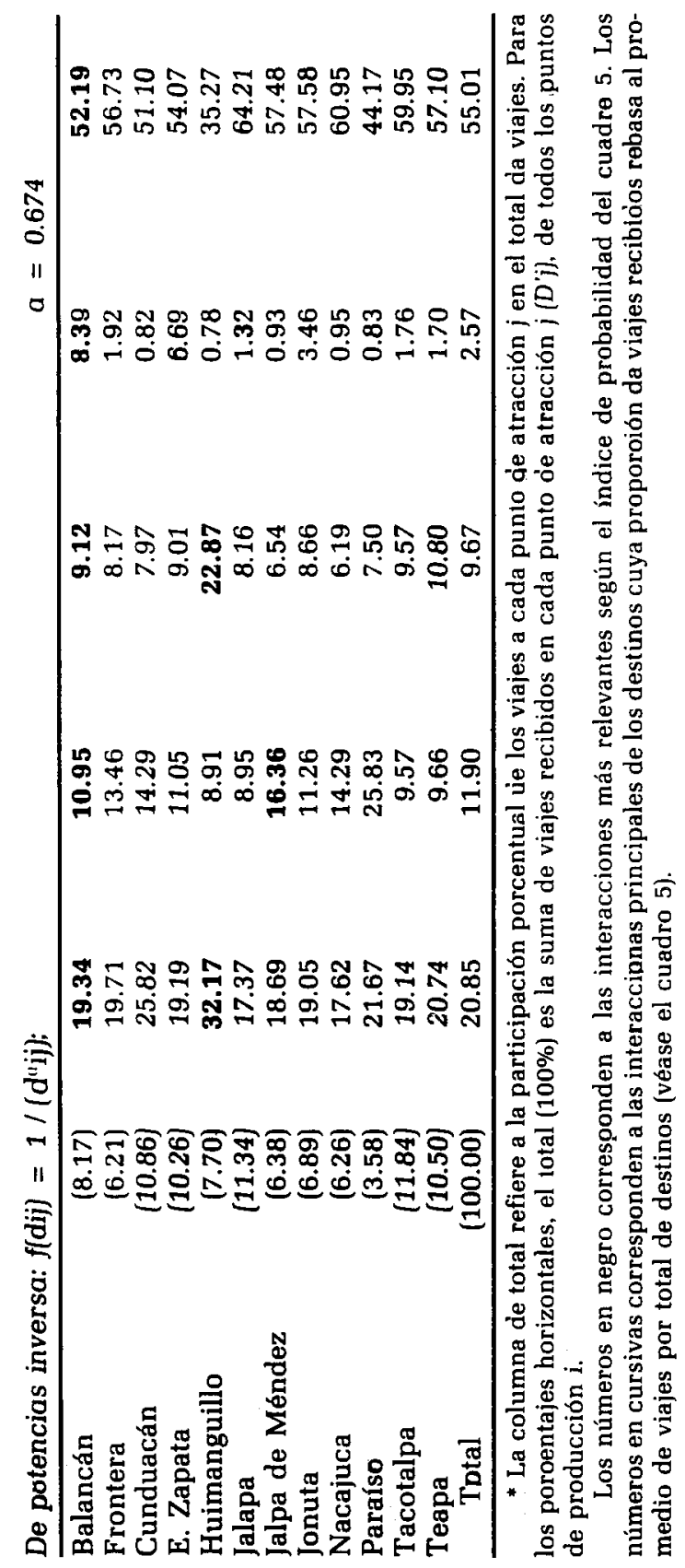




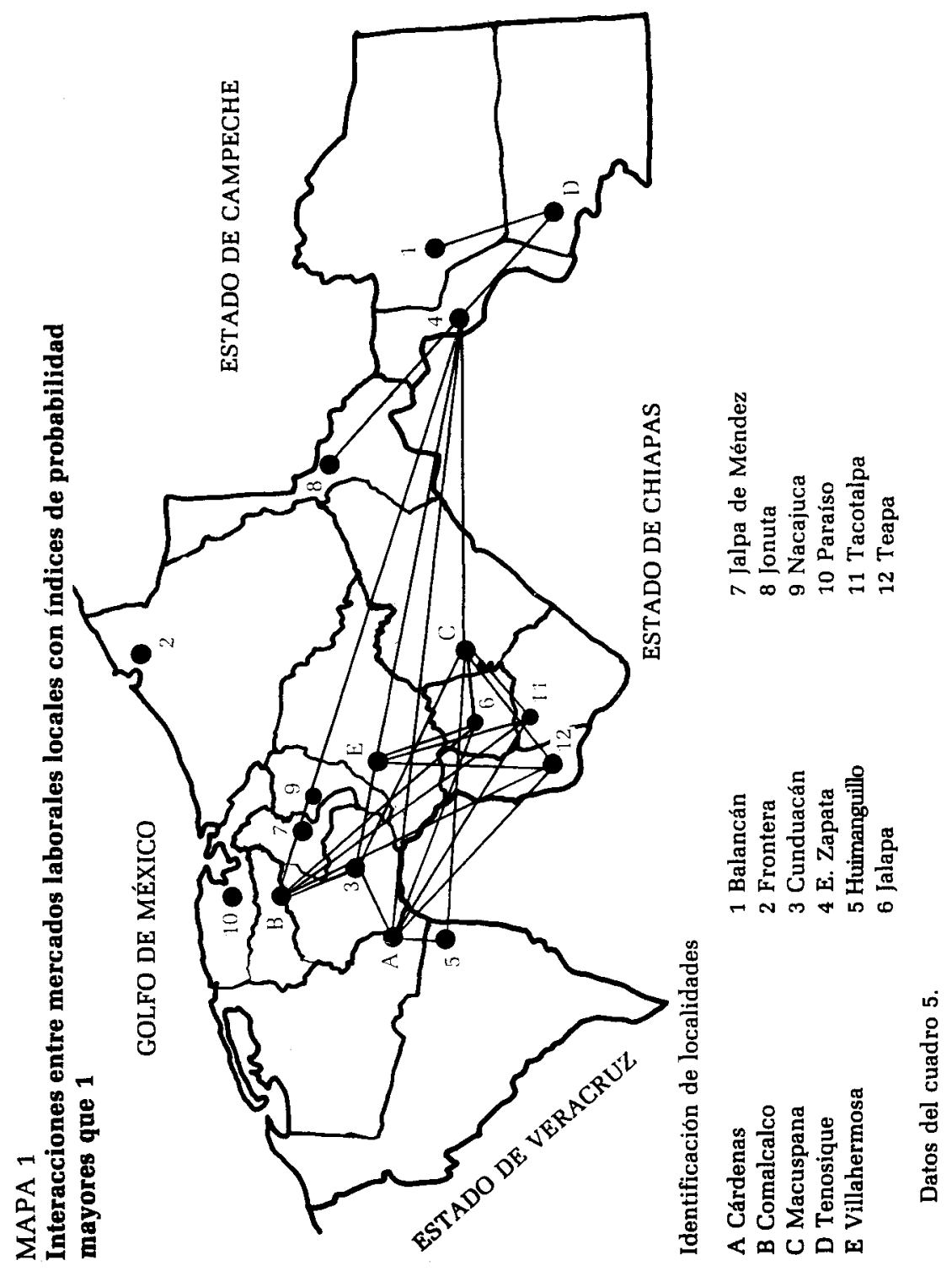


MERCADOS LABORALES MUNICIPALES EN EL ESTADO DE TABASCO 185

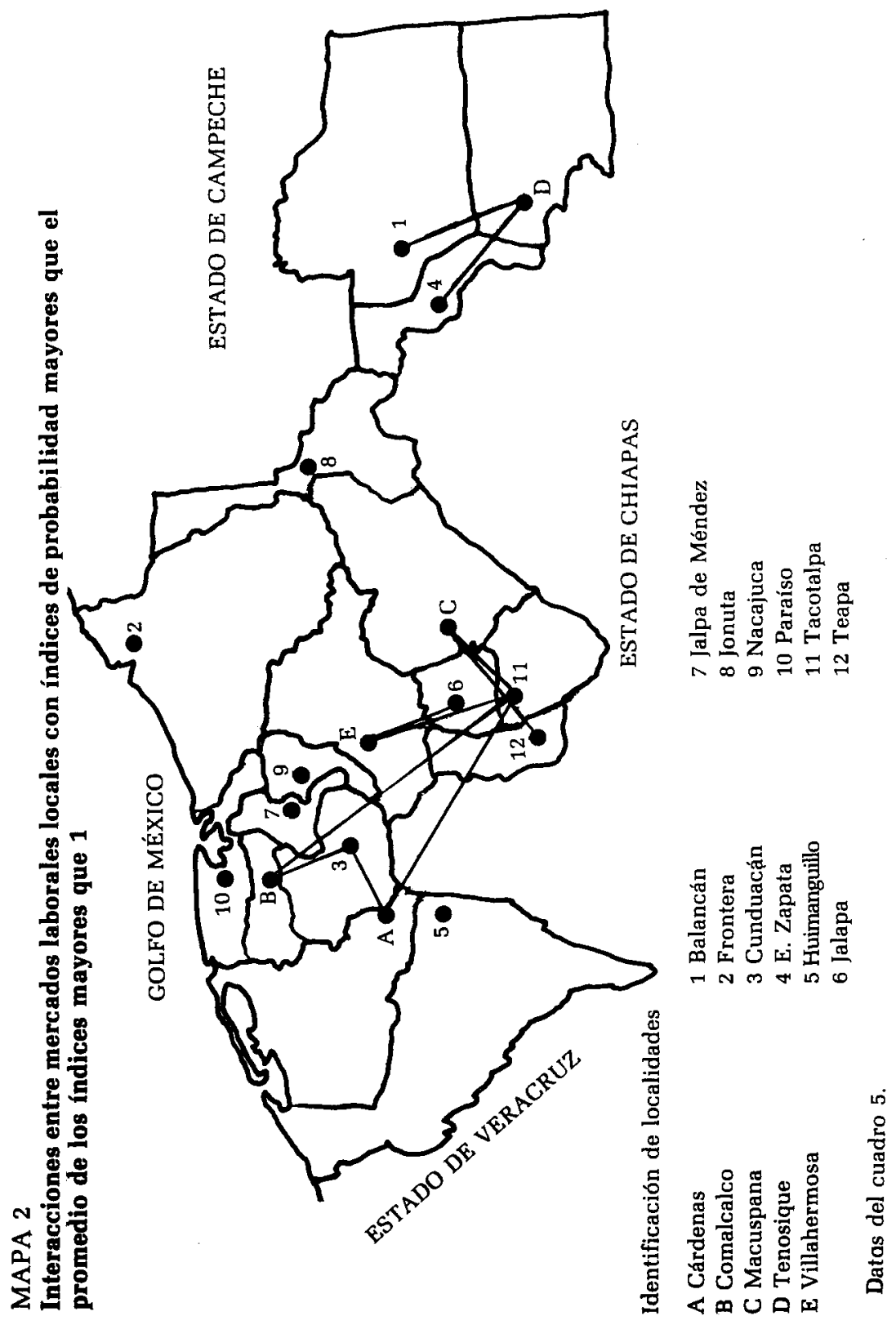


siderarse como un sistema con cierta autonomía en relación con el resto del estado. En especial, Emiliano Zapata, que muestra interacción favorable con todos los puntos de producción, podría pensarse como "cabecera regional" en esta parte del estado, y punto de articulación entre los mercados laborales del centro con los de la zona sur. En particular el índice correspondiente a la interacción de Villahermosa con Emiliano Zapata, a pesar de no rebasar el promedio de los índices de Villahermosa, muestra una magnitud importante que sustenta la inferencia antes anotada.

Análisis de las interacciones según el modelo con restricción en los orígenes y en los destinos

El cuadro 9 presenta los resultados de la estimación de flujos entre puntos de producción i y puntos de atracción $j$. Si consideráramos una distribución homogénea de viajes entre puntos de atracción, los valores de la columna $D^{\prime} j$ serían en todos los renglones de 279. Así, los puntos de atracción con un número de viajes mayor a este número ilustran los principales puntos de atracción. Estos puntos principales corresponden a Cunduacán, Emiliano Zapata, Jalapa, Tacotalpa y Teapa. En ellos, se recibiría a $54.88 \%$ de la PEA desocupada de los puntos de producción. Cabe notar que tanto la función de distancia exponencial negativa como la de potencias inversa, coinciden en esta constatación. Entre estas cinco localidades recibirían, en su conjunto, los siguientes porcentajes de PEA desocupada de cada uno de los puntos de producción: $54.38 \%$, de Cárdenas; $50.88 \%$, de Comalcalco; $56.62 \%$, de Macuspana; $28.74 \%$, de Tenosique, y $55.89 \%$, de Villahermosa.

Según las informaciones del cuadro 9, considerando los puntos de atracción, la PEA desocupada atraída, según las principales interacciones, estaría compuesta de la siguiente manera: en Cunduacán, $24.45 \%$ sería procedente de Cárdenas; 13.74 , de Comalcalco; 9.89, de Macuspana, y 51.10\%, de Villahermosa; en Emiliano Zapata, $16.91 \%$ sería procedente de Cárdenas; 10.20 , de Comalcalco; 8.16, de Macuspana; 7.29, de Tenosique, y $57.43 \%$, de Villahermosa; en Jalapa, $19.69 \%$ sería procedente de Cárdenas; 10.50, de Comalcalco; 9.71, de Macuspana, y 58.79\%, de Villahermosa; en Tacotalpa, $20.35 \%$ sería procedente de Cárdenas; 10.30 , de Comalcalco; 10.55, de Macuspana, y 57.29\%, de Villahermosa, y en Teapa, $21.65 \%$ sería procedente de Cárdenas; 10.26 , de Comalcalco; 11.68, de Macuspana, y 55.27\%, de Villahermosa. Se observa la gran participación que tiene Villahermosa de los destinos a los puntos de atracción. Esto es debido al volumen absoluto que 
tiene la PEA desocupada en esa localidad y que a pesar de tratarse de diferentes distancias, su efecto como "masa" gravitatoria tiene una fuerte presencia en los puntos de atracción. Esta constatación, derivada del propio procedimiento de modelaje, a poya la hipótesis de ampliación de mercados laborales locales en función de los porcentajes de PEA desocupada.

El mapa 3 presenta, en forma gráfica, los flujos que han sido definidos como de mayor relevancia por nuestro análisis.

\section{Conclusiones}

El uso de modelos gravitatorios, así como de cualquier otro método de modelaje, representa un ejercicio de aproximación a la realidad. Por sus características, los resultados se derivan de la propia lógica del modelo, existiendo otros elementos -en este caso de la dinámica económica estatal-, que no son considerados. Sin embargo, a pesar de los argumentos críticos que pueden ser levantados en relación con su validez como instrumentos analíticos, revelan características y dimensiones de los fenómenos en observación que en otro tipo de análisis permanecen ocultos. Así, el modelaje aquí presentado sugiere que las principales interacciones entre mercados laborales locales, a nivel de cabeceras municipales, se localizan en la zona central del estado. Como alternativas para la ampliación intraestatal de mercados laborales, Cunduacán y el eje Tacotalpa-Teapa muestran tener un importante potencial en relación con la ampliación de mercados laborales, alternativos a los de Cárdenas, Comalcalco, Macuspana y Villahermosa.

Por otra parte, se evidencia la existencia de otro ámbito de interacción de mercados laborales en el sur del estado. Emiliano Zapata presenta un papel relevante, ya en el ámbito de la zona sur, ya como punto articulador de ésta con el resto del estado, principalmente con la zona centro.

Las observaciones anteriores sugieren que las posibilidades de ampliación de mercados laborales se localizan hacia el "interior" del estado. Bajo esta consideración, la zona costera, representada por Frontera y Paraíso, no representaría una alternativa de ampliación de mercados laborales alternativos, desde el punto de vista de las principales cabeceras municipales del estado. Incluso Jalpa de Méndez y Nacajuca, con localizaciones próximas a la costa, al igual que las dos localidades antes mencionadas, no presentan interacción con las principales cabeceras municipales del estado. 


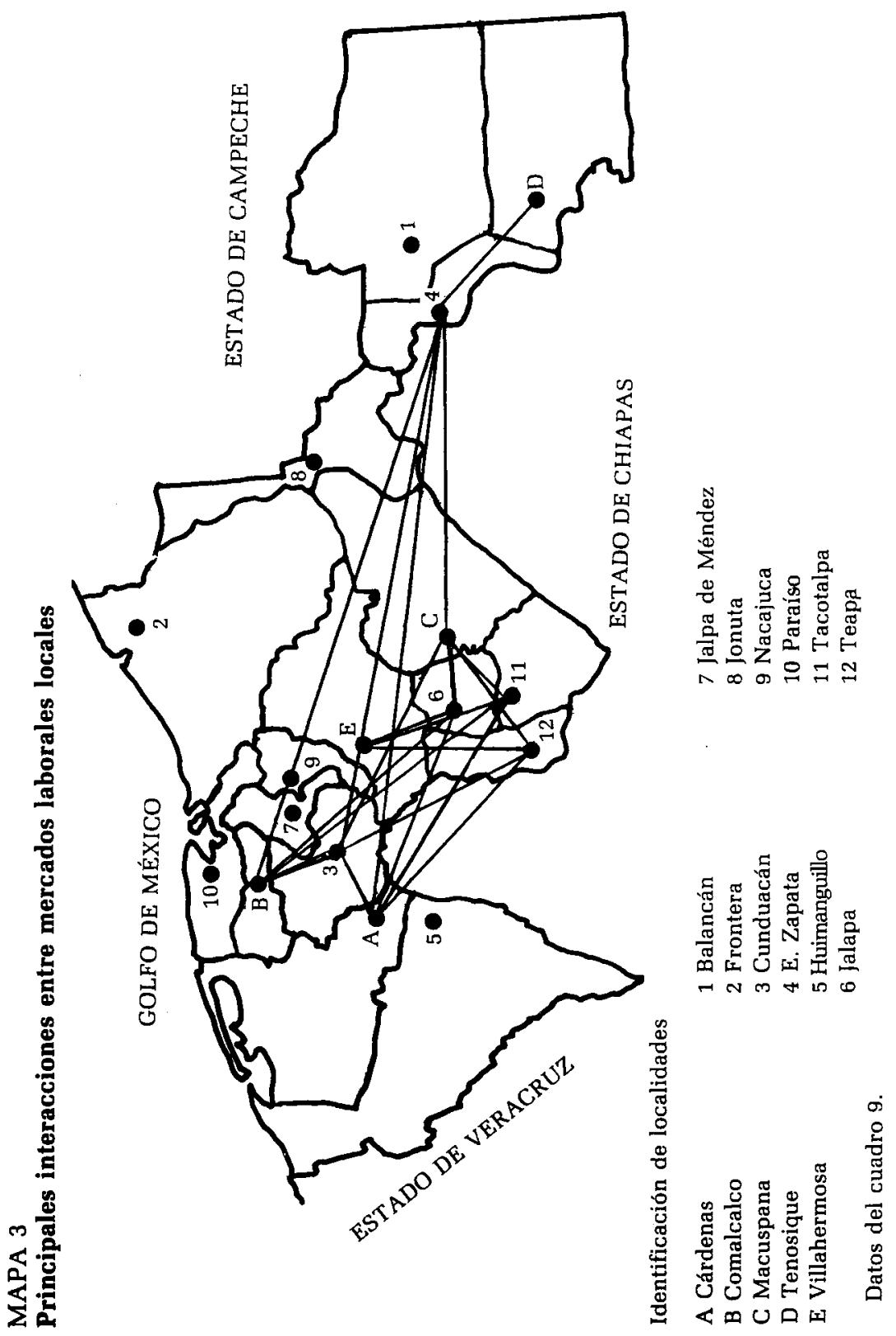




\section{Bibliografía}

Foot, D. (1981), Operational urban modeis: an introduction, Londres, Methuen.

INEGI Instituto Nacional de Estadística, Geografía e Informática (1986), Síntesis geográfica del estado de Tabasco, México, INEGI.

(1991), Tabasco. Resultados definitivos. Datos por locaiidad (integración territorial). XI Censo General de Población y Vivienda, 1990, Aguascalientes, INEGI.

Y1992), Estados Unidos Mexicanos. Resumen General. XI Censo General de Población y Vivienda, 1990, Aguascalientes, INEGI.

Krueckeberg, D. A. y A. L. Silvers (1974), Urban planning analysis: Methods and models, Nueva York, John Wiley and Sons, Inc.

Masser, I. (1972), Analytical models for urban and regional planning, David and Charles, Newton Abbot.

Oppenheim, N. (1980), Applied models in urban and regional analysis, Nueva York, Prentice-Hall, Inc. Englewood Cliffs.

Ottensmann, J. R. (1986), BASIC microcomputer programs for urban analysis and planning, Nueva York, Chapman and Hall.

Reif, B. (1973), Models in urban and regional planning, Nueva York, Intertext Educational Publishers.

Thomas, R. W. y R. J. Huggett (1980), Modelling in geography: A mathematical approach, Totowa, Nueva York, Barnes and Noble Books.

Wilson, A. G. (1974), Urban and regional models in geography and planning, Londres, John Wiley and Sons. 
